\title{
Does Multiple Intelligence Improve Performance? Evidence from a Case at Kampala International University
}

\author{
Zaharah Faridah Kiggundu ${ }^{1}$ \\ ${ }^{1}$ Kampala International University (Nairobi Campus) [E-mail: faredah2005@yahoo.com]
}

\begin{abstract}
This study reports the findings of a study that investigated the relationship between multiple intelligence (MI) and academic performance in higher education. It addresses one question: does MI improve academic performance? Taking the case of the finalist cohort of the university's Faculty of Education of the academic year 2009/2010, data were collected on students' MI and performance. Subsequently, the data were subjected to linear regression analysis. The findings were that the relationship between MI and students' academic performance was not statistically significant. Accordingly, the study lends credence to the traditional conceptualization of the concept of intelligence. Therefore, the paper recommends that higher education institutions continue paying attention to the factors that have traditionally been known to influence academic performance.
\end{abstract}

Keywords: Pedagogical innovation; Student-centred curriculum; Intelligence

\section{$1 \quad$ Introduction}

Intelligence refers to the different learning abilities that students possess. They are classified as; linguistic, logical-mathematical, spatial-visual, musical, interpersonal, bodily-kinaesthetic and naturalistic intelligence (Gardner, 1992) On the other hand, academic performance refers to the degree of success in reaching set learning-related goals. Traditionally, psychologists have discussed intelligence as a general capacity for comprehension and reasoning that manifests itself in various ways and abilities such as memory span, arithmetic skills and vocabulary knowledge. These psychologists noticed that some students tended to score higher than others on academic achievement tests so they characterized these students as being more intelligent. However, contemporary research (e.g. Gardner, 1992) contends that there is MI, meaning that there are no bright and dull students. Rather, students are talented 
differently, with the ability to excel at different things and requiring support when it comes to other aspects of learning.

The goal of education being the all round development of students, the inference here is that educators are obligated to accept that each learner is unique and brings some strengths and weakness to each learning experience. Therefore, higher education institutions (HEIs) and their lecturers need to make the learning process student centred.

On the contrary, for most of the last century, education has been content/instructor- rather than student-centred (Gardner, 1999). Education tended to be merely informative whereby students were treated merely as pitchers into which the lecturer poured information. In African HEIs, some lecturers have expected their students to remain quiet and receptive throughout the teaching and learning process. According to Gardner, (1992), the problem with this attitude towards students is that students' ability to contribute to the pedagogical process and to exercise initiative and innovation is underrated, with the result that the teaching and learning process does not unlock their full potential. Specifically, critics have argued that failure to appreciate students' MI has affected their academic performance and vice-versa. In higher education, it has been argued that, in a class situation, it means a lot if a lecturer facilitates learning rather than pumping knowledge into the students' brains.

Subsequently, there is evidence that, in many HEIs, pedagogical approaches are metamorphosing from instructor and single intelligence based to learnercentred and MI based (see, for example, Linda, 1997). Kampala International University, the largest of the new HEIs in Uganda (Ssempebwa et al., 2011), is one of these institutions. The university's philosophy of instruction derives from the conceptualization of MI described above. It "regards each student as a unique individual who brings to the learning environment certain strengths and ideals. It is the role of the University to assist students to actualize their strengths. The university ensures that the educational experiences of students are designed to produce productive graduates who can contribute positively to the overall wellbeing of society. Holistic development and a strong, positive intellectual development is what the university strives to inculcate in each student" (KIU, 2009).

However, hitherto, the relationship between MI and students academic performance, from which the university's philosophy of education derives, had not been examined. Thus, this study was conducted to fill this gap. Taking the case of the finalist cohort of the university's Faculty of Education of the academic year 2009/2010, data were collected on students' MI and performance. Subsequently, the data were subjected to linear regression analysis. The findings were that the relationship between MI and students' academic performance was not statistically significant. Accordingly, the study lends credence to the traditional conceptualization of the concept of 
intelligence, so HEIs are urged to continue paying attention to the factors that have traditionally been known to influence academic performance.

\section{$2 \quad$ Methodology}

\subsection{Study Area, Population and Sample}

The study was carried out at Kampala International University Main Campus in Kampala. Data were collected on the MI and academic performance of 123 of the 180 finalist students of Bachelor of Arts (BA) and Bachelor of Science (BSC) with Education for the academic year 2009/2010. The students were drawn from the four departments in the Faculty (Table 1).

Table 1: Distribution of Sample by Department

\begin{tabular}{ll}
\hline Department & Sample \\
\hline Educational Foundations & 50 \\
Arts and Humanities & 30 \\
Sciences & 20 \\
Languages & 10 \\
Total & $123^{*}$ \\
\hline
\end{tabular}

${ }^{*} \mathrm{~N}=180$; Sample size based on Krejcie \& Morgan (1970)

From each of the departments, the students served with the questionnaire were randomly. The selection was done using the computer method and relevant class lists as sampling frames. One hundred and ten of the 123 questionnaires administered were retrieved, representing a response rate of $89 \%$.

\subsection{Data Sources and Collection Instrument}

Data on the students' MI were elicited using a questionnaire (Cronbach's alpha $=.79$ ). The questionnaire was constructed using attributes of MI adapted from related literature, so the instrument was assumed to be valid. The questionnaire focused on linguistic, logical-mathematical, spatial, musical, bodily kinaesthetic, interpersonal, intrapersonal and naturalistic the questionnaire was interpreted in the following manner. Number $1,8,17$ refers to students with linguistic intelligence, 6, 12, 18 those with music intelligence, 3, 7, 15, as those with logical-mathematical, 4, 11, 13 spatial, 5, 9, 14 indicated those with bodily-kinaesthetic, 10, 16, 20 to those with intrapersonal, 2,19,24 as those with interpersonal and 21, 22, 23 as those with naturalistic intelligence. Thus when the three were encircled, the student was be said to be strong in that particular 
kind of intelligence even if he or she has not fully developed it. This instrument was chosen because, predetermined and standardized questions would be simple and eases time for respondents as it improved the report between the researcher and the respondent. A set of alternatives ranging from "Seldom", "Often", "Sometimes" and "Always" were assigned numerical values ranging from 1 to 4 respectively and mean scores on aspects of MI categorized among the alternatives. Students' academic performance was looked at in terms of their scores in university examinations. These scores were taken to be a valid indicator of academic performance (see, for example, Kassahun, 2008; Israel, 2005).

\subsection{Analysis}

The students' scores on the attributes of MI surveyed were computed into means. These means were distributed among the categories described in 2.2 (i.e. "Seldom", "Often", "Sometimes" or "Always") to determine the extent to which the participants typified the given attributes of MI. These categorizations were computed into an index on MI. To determine whether MI improves academic performance, this index and the findings on the students' academic performance were subjected to linear regression analysis.

\subsection{Ethical Considerations}

Both the data on students' MI and academic performance were obtained with the informed consent of the dean of the Faculty of Education. In addition, the identity of subjects was concealed and the findings reported in aggregates, respectful to the confidential nature of subjects' academic performance.

\section{$3 \quad$ Findings}

The findings on the relationship between MI and students' academic performance are summarised in Table 2.

Table 2: MI and Academic Performance

\begin{tabular}{llllll}
\hline Variable (indices) & Sample & Mean & Std. Deviation & r value & Sig. \\
\hline Students performance & 80 & 3.50 & 0.482 & \multirow{2}{*}{0.125} & \multirow{2}{*}{0.277} \\
Ml index & 78 & 2.64 & 0.375 & & \\
\hline
\end{tabular}

The results in Table 2 show that the relationship between MI and students' academic performance was not statistically significant $($ sig. $=0.27)$. This implies that MI may not lead to improved academic performance. 
Table 3: Analysis of Variance

\begin{tabular}{|c|c|c|c|c|c|c|c|c|}
\hline & Sum of squares & \multicolumn{3}{|c|}{ Df Mean square } & F statistic & Sig. & \multicolumn{2}{|c|}{ Adjusted $\mathrm{R}^{2}$} \\
\hline Regression & 0.327 & 1 & 0.327 & & & & & \\
\hline Residual & 17.895 & 76 & 0.235 & & 1.390 & 0.242 & 0.005 & \\
\hline Total & 18.222 & 77 & & & & & & \\
\hline \multicolumn{9}{|c|}{$\begin{array}{l}\text { *Predictors: (Constant), MI } \\
\text { "Dependent Variable: STUDENTS PERFORMANCE }\end{array}$} \\
\hline \multicolumn{9}{|c|}{ Table 4: Coefficients } \\
\hline & \multicolumn{3}{|c|}{ Unstandard coefficients } & \multicolumn{3}{|c|}{ Standard coefficients } & \multirow[t]{2}{*}{$\mathrm{t}$} & \multirow[t]{2}{*}{ Sig. } \\
\hline & Std & \multicolumn{2}{|c|}{ Std. Error } & B & & & & \\
\hline (Constant) & 3.163 & \multicolumn{2}{|c|}{0.293} & & & & 10.790 & 0.000 \\
\hline $\mathrm{MI}$ & 0.006 & \multicolumn{2}{|c|}{0.005} & 0.134 & & & 1.179 & 0.242 \\
\hline
\end{tabular}

Accordingly, the study lends credence to the traditional conceptualization of the concept of intelligence. The inference here is that HEIs should continue paying attention to the factors that have traditionally been known to influence academic performance (e.g. learning environment and quality of teachers). Educators have a responsibility to nourish their learners and ensure their growth. Thus, HEIs need to take a hard look at how they can reach and teach their students to realize their full potential.

\section{References}

Gardner, H. (1992). Frames of mind. New York: Penguin Putnam Publishers.

Gardner, H. (1999). The Disciplined Mind. New York: Penguin Putnam Publishers.

Israel, H. (2005). Continuous assessment as a tool in curriculum development. South African Journal of Higher Education 19 (Special issue), 1419-1426.

Kassahun, D. (2008). Standardization techniques for grade-inflation problems at higher educational institutions of Ethiopia: the case of Addis Ababa. Assessment and Evaluation in Higher Education 33(1): 33-44.

KIU (2009). Order of proceedings for the $6^{\text {th }}$ graduation ceremony: congregation for the conferment of degrees and award of diplomas. Office of the Director of Academic Affairs, KIU.

Krejcie, R. V., Morgan, D. W. (1970). Determining sample size for research activities. Educational and Psychological Measurement 30, 607-610.

Linda, C. (1997). A theme on how teachers interpret MI. Retrieved 15 May 2011 from: http://www.newhorizons.org/strategies/mi/hoer2.htm 
Ssempebwa, J., Eduan, W., Mulumba, F. N. (2011). Effectiveness of University Bridging Programs in Preparing Students for University Education: A Case from East Africa. Journal of Studies in International Education. DOI: $10.1177 / 1028315311405062$. 